\title{
ПРИЧИНЫ КРИЗИСА 2008 ГОДА
}

\author{
Марьянов Дмитрий Вадимович \\ Аспирант, Московский финансово-юридический \\ университет (МФЮА) \\ pol2244@yandex.ru
}

\section{CAUSES OF THE 2008 CRISIS}

D. Maryanov

Summary. The economy has the ability to develop cyclically: there are crises, booms, "booms". People seek a boom cycle to maintain their wellbeing, and the government wants the economy to always develop and improve, but it is obvious that the country's economy cannot always be stable, but faces a different problem, which leads to a recession and an economy. They have long been struggling with crises, but even such developed countries as the USA, Great Britain, France, Germany and other countries have not invented "medicines" for treating economic crises.

Keywords: crisis of 2008, global crisis, causes of the crisis, economies of countries.

$\Pi$ роблема экономических кризисов актуальна в настоящее время как в зарубежных странах, так и в России, и за сравнительно небольшой период времени 10-15 лет, страны находятся в состоянии экономических кризисов, которые то ослабевают, то усиливаются.

Анализ последних исследований и публикаций. В течение последних десятилетий начали появляться труды посвящены изучению и анализу кризисных процессов в глобальной экономике. Можно выделить работы следующих авторов: П. Кругман, Д. Корсетти, А.Сбрациа, Д. Периколи, Д. Сорос, М. Баркли, А. Бернак, П. Презенте, Н. Рубини.

Цель статьи. Главной целью этой работы является исследование теоретических и методологических основ возникновение экономических кризисов в условиях современных мирохозяйственных отношений ведущих стран мира, какая страна больше всего в своей экономике развила экономический кризис и соответственно, как повлиял кризис 2008 г. на страны Европы и мира.

Для достижения этой цели было поставлено такие задачи:

- выявить современные тенденции и угрозы развертывания мировых экономических кризисов в условиях глобализации мировой экономической системы;
- проанализировать современные глобальные процессы с точки зрения развития мировых цивилизационных процессов в контексте обеспечения международной стабильности и определить перспективы преодоления мировых экономических кризисов (на примере кризиса 2008 г.), в контексте международного антикризисного управления.

Изложение основного материала. Термин «кризис» происходит с греческого языка, что означает «выбор, решение, решающий момент» и во многих случаях, в том числе и в иностранных языках, используется как синоним слов «ухудшение», «разрушение» и всегда в негативном смысле.

Однако «кризис» в отношении экономики означает промежуток времени или событие, после соответствующей реакции на которые происходит коренное изменение устойчивых, долговременных условий функционирования экономической системы.

Современный мировой экономический кризис берет начало с 2008 года. Она имеет существенные отличия и особенности по сравнению с известными до сих пор циклическими кризисами. Мировой экономический кризис начался в 2007 г. в США как ипотечный. В 2008 г. он охватил всю банковскую систему и превратилась 
в мировой финансовый кризис, который обострил глобальные экономические проблемы не только во всех постиндустриальных странах, но и в странах, экономика и торговые отношения которых плотно связаны с экономикой США и странами Европы.

Мировой кризис, зародилась в США как кризис рынка недвижимости и производных финансовых инструментов, довольно быстро это задела большую Британию, вскоре полностью разрушила успешную экономику Исландии - «страны наивысшего благосостояния». Серьезно пострадали практически все страны Европы, впоследствии кризис дошел и до самых отдаленных уголков, захватив даже Австралию.

Ощутимые потери понесли также страны с якобы прекрасно развитой финансово-банковской системой, однако без серьезной основы в реальном секторе экономики (страны Балтии).

Среди основных причин мирового кризиса эксперты выделяют следующие:

- чрезмерно экспансивную денежную политику Федеральной резервной системы (ФРС) США;

- наличие огромного дисбаланса в мировой экономике, в частности, большой профицит во внешней торговле Китая, значительный торговый дефицит в США;

- недостатки системы управления рисками в инвестиционных банках;

- несовершенство регулирования финансовых рынков на национальном и международном уровнях.

Обеспечение финансовой стабильности требует системного подхода ко всем составляющим финансовой системы в их взаимодействии и под влиянием внешних факторов, порожденных глобализационными процессами.

Современная геоэкономическая ситуация требует разработки принципиально новых подходов к антикризисному управлению с учетом последствий глобального финансового кризиса, которая не обошла и РФ.

В связи с этим, растет важность разработки и обоснования таких механизмов управления, которые дали бы возможность минимизировать возможность возникновения финансовых кризисов и обеспечить финансовую устойчивость банковского сектора.

Так, П. Кругман [11] определяет основной причиной возникновения финансовых кризисов неравновесие платежного баланса страны. Эта теория получила название «кризис первого поколения». Г. Флуд и Н. Марион предложили теорию кризисов второго поколения, в ней сущность кризисов не была изменена, но предложен новый подход к их рассмотрению.

Авторы обосновали влияние структурных и политических факторов на скорость распространения кризисных ситуаций $[11,107]$. По мнению А. Мельника [4], возникновение финансовых кризисов объяснялось несоответствием макроэкономического развития отдельных государств и отклонением макроэкономических показателей от нормативных значений, а именно таких показателей, как соотношение денежной массы (M2) к величине валютных резервов, объем задолженности государственного сектора, изменение реального валютного курса, объемы кредитования.

Дальнейшие научные исследования мировых финансовых кризисов определяли их сущность и в значительной степени уделяли внимание стабильности финансового рынка и потокам капитала.

Мировой финансовый кризис 2007-2009 гг., прошел три этапа в своем течении.

Первая волна распространилась в 2007 г., когда на мировых фондовых рынках произошло первое падение фондовых индексов ведущих банков и финансовых компаний.

Первый этап кризиса - с июля 2007 г. к августу 2008 г.- характеризовался развитием американского ипотечного кризиса, первыми банкротствами. Мировая финансовая система понесла в этот период потери примерно на 800 млрд. дол. США.

Убытки банков в течение этого периода составили 587 млрд. дол. США, другие же секторы финансового рынка потеряли 160 млрд. дол. США.

Общей тенденцией, которая наблюдалась в течение 2008 г. на мировых фондовых рынках, было значительное ухудшение основных показателей биржевой торговли. В частности, происходило снижение капитализации большинстве фондовых площадок мира и падение биржевых индексов. Это связано, прежде всего, с мировым экономическим кризисом, которая имела негативное влияние как на развитые рынки, так и на развивающиеся рынки.

Качественное изменение произошло в мае 2009 г. на мировом фондовом рынке, когда был зафиксирован активный рост главных индексов, невиданное на многих биржах за последние шесть лет. В результате в деловом мире широко распространилось мнение, что хуже период экономического спада 2009 г. остался уже позади (табл. 1). 
Таблица 1. Этапы развития мирового кризиса США

\begin{tabular}{|c|c|c|c|c|}
\hline Термины & Рынки возникновения & Причины & Рынки охвата & Прицепные \\
\hline Лето 2017 г. & Ипотечный рынок США & $\begin{array}{l}\text { Массовые невозвраты } \\
\text { платежей по ипотечным } \\
\text { кредитам }\end{array}$ & $\begin{array}{l}\text { Европейский рынок } \\
\text { ипотеки }\end{array}$ & Секьюритизация \\
\hline $\begin{array}{l}21.01 .2008 \text { г. } 22.01 . \\
2008 \text { г. }\end{array}$ & $\begin{array}{l}\text { Фондовые рынки Европы } \\
\text { и США }\end{array}$ & $\begin{array}{l}\text { Публикация пессимистичных } \\
\text { прогнозов относительно } \\
\text { «охлаждения» европейской } \\
\text { и американской экономик }\end{array}$ & $\begin{array}{l}\text { Фондовые рынки Азии } \\
\text { и стран ВКОС }\end{array}$ & Ипотеки \\
\hline Сентябрь 2008 г. & Банковской рынок США & $\begin{array}{l}\text { Банкротство Lehman Brothers, } \\
\text { продажа Merrill Lynch }\end{array}$ & $\begin{array}{l}\text { Европейский банковский } \\
\text { рынок }\end{array}$ & $\begin{array}{l}\text { Транспарентность } \\
\text { фондовых рынков }\end{array}$ \\
\hline Октябрь 2008 г. & $\begin{array}{l}\text { Фондовый рынок США } \\
\text { (рекордное падение } \\
\text { биржевых индексов) }\end{array}$ & $\begin{array}{l}\text { Отклонение в первом или } \\
\text { анне проекта закона США } \\
\text { о поддержке финансового } \\
\text { рынка страны }\end{array}$ & $\begin{array}{l}\text { Фондовые рынки } \\
\text { Европы, Азии, стран } \\
\text { ВКОС, в том числе } \\
\text { и Украины }\end{array}$ & $\begin{array}{l}\text { Финансовые проблемы } \\
\text { банковских учреждений } \\
\text { Великобритании, } \\
\text { Германии, Франции }\end{array}$ \\
\hline Июль 2009 г. & Финансовой рынок США & $\begin{array}{l}\text { Монетарная политика США, } \\
\text { приведшая к девальвации } \\
\text { доллара }\end{array}$ & $\begin{array}{l}\text { Фондовые рынки } \\
\text { Америки, Европы и Азии } \\
\text { (падение индексов) }\end{array}$ & $\begin{array}{l}\text { Эффект «домино», начало } \\
\text { рецессии в США }\end{array}$ \\
\hline
\end{tabular}

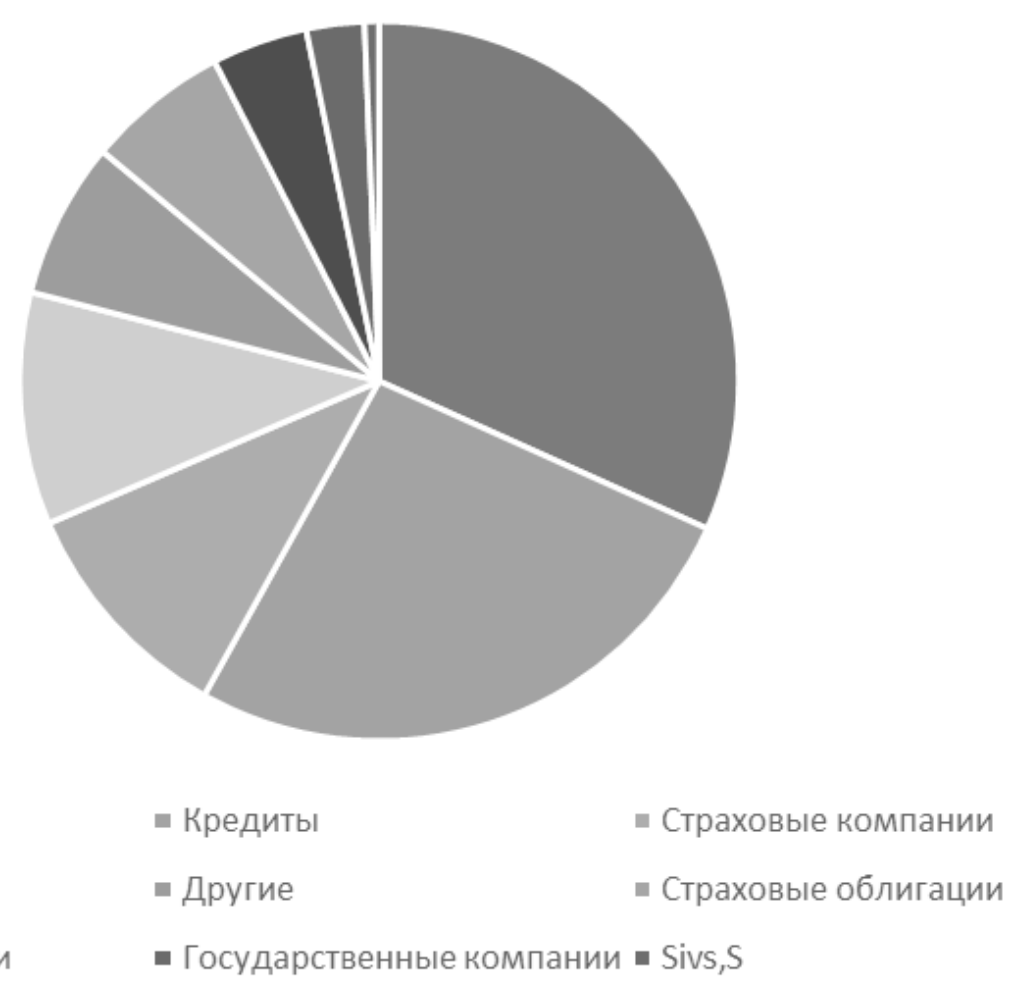

Рис. 1. Объем потерь в мировой финансовой сфере по типу секторов и видам операций, июль 2007 г.— август 2008 г. (млрд. дол. США) 
Вторая волна стартовала в начале 2008 г., когда падение фондовых рынков мира, продолжавшееся, обусловило переориентацию финансовых потоков из одних активов в другие, в частности сырьевые и энергетические. Эти активы стали более привлекательными, что сразу стимулировало существенный рост цен на сырьевые ресурсы.

Второй этап-кризис ликвидности-протекал «волнами», однако внутри сентября 2008 г. он приобрел определенную стабильность.

Банки торговали только «чужими» деньгами центральных банков, но своих никому не доверяли. Банкротство Lehman Brothers, вызвано, по мнению экспертов, исключительно теоретическими соображениями - предупредить «моральный риск», то есть не снимать ответственности с участников рынка - стало свидетельством недостаточного понимания глубины современного кризиса: оно напугало всех, поскольку показало, что нет более надежных брендов [7; 12$]$.

Для того, чтобы лучше понять, как именно экономический кризис начала развиваться, можно проследить за основными этапами развития мировой кризиса в табл. 1.

Федеральная резервная система, пытаясь предупредить торможение экономики и повлиять на стоимость кредита как предпосылку экономического спада, с сентября по декабрь 2007 года снизила базовую ставку с $5,25 \%$ до $4,25 \%$.

Доллар стал ослабевать экспорт - расти, а с ним повысился и ВВП: в третьем квартале $+4,9 \%$ против $+3,8 \%$ во втором квартале. Финансовые ресурсы начали перетекать на фондовый рынок, поскольку снижение базовой ставки привело к росту его капитализации - индекс Доу-Джонс достиг в октябре 2007 года рекордного значение 13 <905 пунктов, а также на рынки сырья, золота и на внешние финансовые рынки, в том числе Европы и России.

Третью волну мирового кризиса можно было наблюдать в конце 2008 г. Третий этап - это паралич кредита, вызванный кризисом ликвидности и недоверием внутри банковской системы. На фоне падения объемов производства, торговли и капиталовложений продолжалась борьба национальных правительств, бизнеса и международных организаций с мировым финансовым и экономическим кризисом.

Результатам этого этапа стала серия банкротств ведущих мировых финансовых компаний и распространение финансового кризиса на реальный сектор мирового хозяйства, падение спроса на мировых рынках и, как ре- зультат, обвал цен на сырьевых рынках, стагнация ведущих экономических систем.

В августе-сентябре цена на металл в среднем по восьми регионам мира упала на 18,3\%, цены на нефть снизились на 26,5\%. На валютном рынке начались девальвационные процессы, и уже в сентябре международные валютные резервы сократились на 0,6 млрд. дол. США. Как один из факторов, что ускоряют инфляцию, в сентябре снова начали усиливаться негативные инфляционные ожидание. На наличном валютном рынке сформировалось значительное отрицательное сальдо продажи/ покупки населением иностранной валюты на уровне 1321 млн. дол. США.

Третья волна мирового финансового кризиса заставила правительства ведущих стран пересмотреть свою политику в отношении финансовых рынков. В частности, правительства США, Великобритании, Германии, России, стран Бенилюкса приняли решение о государственную поддержку отдельных финансовых учреждений, которые переживали финансовые трудности [12]. Можно выделить три основных направления мероприятий, которые проводились с сентября 2008 г.: предотвращение разрушения важных кредитных институтов с помощью «мягкой национализации»; предотвращения «набега вкладчиков» на сберегательные учреждения; предотвращение протекционизма в мировой торговли.

В ходе финансового кризиса действия финансовых регуляторов отдельных стран были не до конца понятными, поскольку у них не было единой четкой стратегии «выхода». В общем большинство из них взяли за основу идею сохранения эффективности коммерческих банков, реализовать которую можно было путем широкомасштабного государственного вмешательства.

Однако, как показал опыт, чрезмерное огосударствление банковской системы снизило ее эффективность.

Благодаря осуществленным мерам удалось предотвратить массовую атаку вкладчиков на сберегательную систему.

В то же время «финансовый национализм» привел к увеличению защиты депозитов, национализации или «тихой» покупки зашатавшихся банков. При дальнейшем развитии кризиса в реальной экономике потери в сберегательной системе могли накапливаться, как и в секторе ипотеки.

Важное место в экономических дискуссиях занимает вопрос причин кризиса. Преобразование американской валюты в международную, причем без каких-либо обязательств и ответственности, предоставило США 


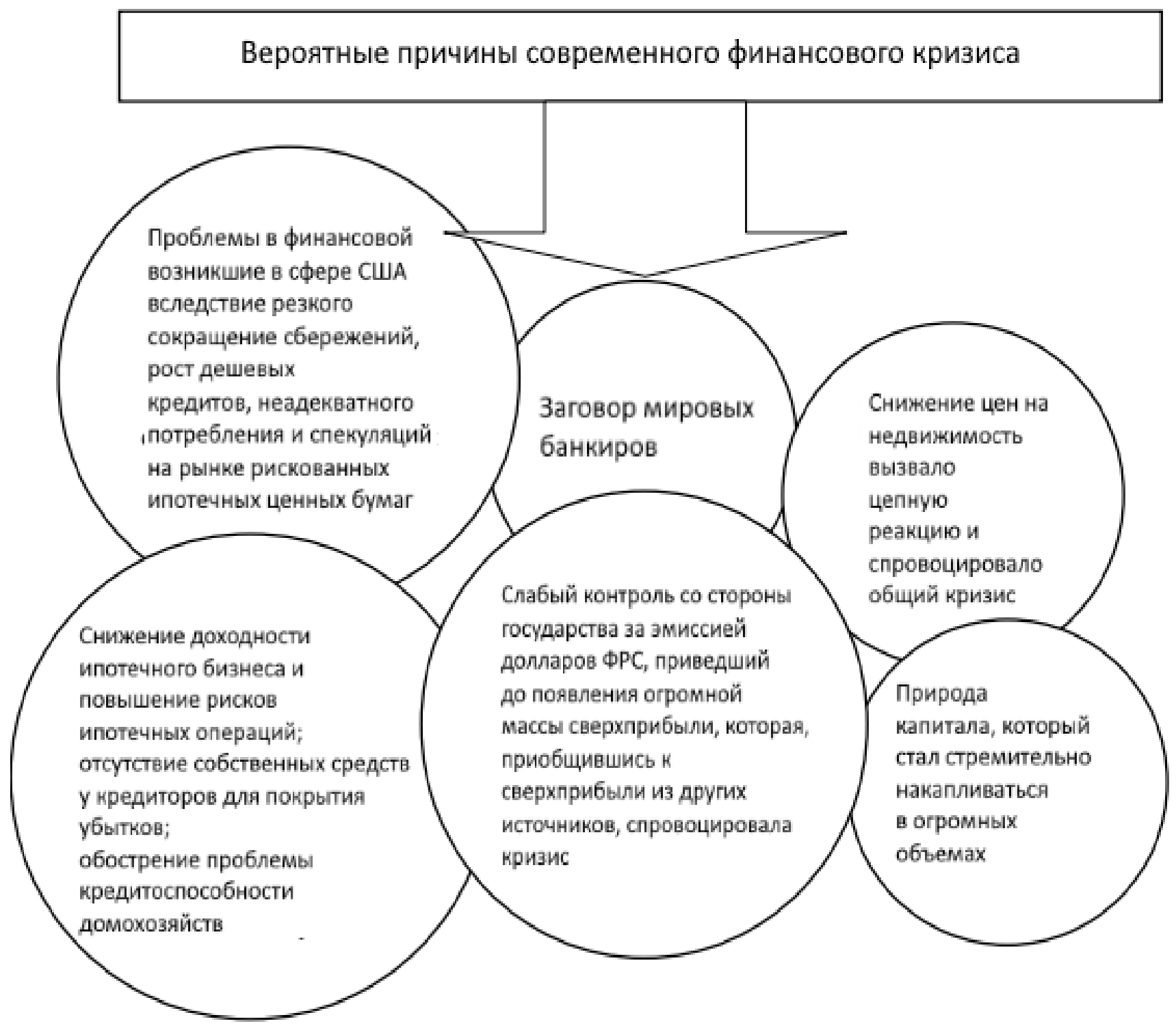

Рис. 2. Вероятные причины современного финансового кризиса

огромных выгод и преимуществ в осуществлении кредитной экспансии, создав значительные возможности ее бизнесменам не только для злоупотреблений, но и для мошенничества. Ничем не гарантированная жизнь в долг одной из крупнейших мировых экономик и ее неспособность рассчитаться с банками, положило начало обвалу американской экономики. Цепная реакция вызвала огромные экономические шоки и в нашей стране: финансовый кризис ударил по большинству отраслей, но, прежде всего, по рынку недвижимости (рис. 2) [3].

Снятие ограничений на недопущение дополнительной эмиссии спровоцировало инфляцию в мировых масштабах.
Сегодня международная валютная система не имеет механизма для предотвращения устойчивом торговом дисбаланса. Поэтому США продолжали накапливать дефицит текущего счета, который с 1980 г. достиг гигантской суммы - 3 трлн. дол. США.

Этот дефицит служил экономической субсидией остальному мировому сообществу, наводняя при этом страны долларами, которые стали новым международным резервным активом.

Впрочем, это не могло остановить ипотечный кризис. В ноябре 2007 года новых домов было продано на 34,4\% меньше, чем в ноябре 2006 года. Строительная отрасль стала останавливаться, страдая от падения спроса и долгов. 
Обнародован в январе 2008 года отчет Всемирного банка зафиксировал замедление роста мировой экономики в 2007 году: +3,6\% против +3,9\% в 2006 году, а главными причинами этого названные кредитный кризис, подорожание базовых товаров, энергоносителей и курсовой фактор основных валют.

ВВП Соединенных Штатов в 2007 году вырос лишь на 2,2\% - самый низкий показатель за последние пять лет. Падение объемов продаж новых домов за 2007 год составил $26 \%$, а цены на них упали на $10 \%$. Инфляция составила 4,1\%, возросла безработица.

Вместе с тем, девальвация доллара привела к росту в 2007 году американского экспорта на 12,2\%, который составил 1620 миллиардов долларов, потеснив позиции ЕС и Японии, а импорта - на 5,9\%, который достиг 2 <330 миллиардов долларов. С сентября 2007 г. доллар вследствие финансовых оттоков начал девальвировать относительно евро особенно сильно, и эта девальвация продолжалась до июля 2008 г., когда его курс достиг 1,6 \$/€.

Большая часть импорта была из Китая и Южной Америки. ФРС ответила на это очередными снижениями базовой ставки, доказав ее в апреле до $2 \%$, а к концу 2008 года - до 0,25\% в надежде стимулировать экономику и удержать капиталы. на фондовом рынке от перетока на товарные рынки и роста цен на них [3].

Потеря заемщиками США кредитоспособности, а банками ликвидности привели в 2007-2008 годах до значительных финансовых убытков европейских банков. Финансовая паника в США и политика ФРС на снижение базовой ставки вызвали побег займов в III-IV кварталах 2007 года назад в Европу и укрепление евро.

В 2009 г. Президент США высказал некоторые положения, на основе которых будет осуществляться борьба с кризисом. Палата представителей приняла бюджет страны на 2009-2010 финансовый год в размере 3,6 трлн. дол. и с дефицитом в 1,2 трлн. долл. Дефицит бюджета США в период с октября 2008 г. по февраль 2009 г. составлял 765 млрд. дол. «Сдувать» дефицит планируется как за счет заморозки государственных расходов по многим статьям (кроме социального блока), так и с помощью введения дополнительных налогов на «виновников кризиса» - банки и корпорации. Новые налоги ждут и богатых американцев, зарабатывающих более 250 тыс. долларов в год.

Итак, можно сделать вывод, что правительство США сознательно развернул экономический кризис, который затем повлияла на ведущие страны мира, сокращая базовую ставку, снижая курс доллара, экспорта, рост цен на товарные услуги.
США своей политикой и развитием экономического кризиса повлияла на экономическую систему в мире, в частности страны ЕС. Сформировались некоторые вторичные предпосылки общего экономического кризиса.

1. Движение валютных курсов, что вызвало изменения условий международной торговли с соответствующим влиянием на национальные экономики.

2. Перераспределение финансовых ресурсов между финансовым, фондовым и товарным рынками, спекулятивный рост цен на основные ресурсы, увеличивал общую инфляцию, ухудшал кредитные условия, стоимость производства и потребления.

3. Распространение последствий финансового кризиса в США на остальной мир

Причинами торможения экономики ЕС стало замедление развития США как крупнейшего торгового партнера, рост цен на энергоносители и базовые товары, укрепление евро подрывает конкурентоспособность европейских товаров.

К 2007 году европейские банки активно кредитовали банки США, в том числе под ипотечное строительство. Инфляция в ЕС в 2007 году достигла 3,1\%, в том числе благодаря повышению базовых ставок, и это стало одним из факторов кредитного кризиса в Европе.

Экономическое развитие Европы в 2007 году замедлился: $+2,6 \%$ ВВП против $+2,9 \%$ в 2006 году.

Инфляция в еврозоне в январе 2008 года составляла 3,2\% в годовом выражении из-за роста цен на энергоносители и базовые товары при нормативном максимуме $2 \%$. Одна из стран, на которую повлияла экономическая кризис является Германия.

Выводы и предложения. Мировой финансовый кризис начался в 2007 году с обвала рынка ипотечных кредитов в США. Обвал рынка недвижимости, стремительный рост количества невозвращенных кредитов, банкротство кредитных фондов, списание мировыми банками сотен миллиардов долларов убытков, обвал фондовых рынков, рост цен на энергоносители, ускорение темпов мировой инфляции и снижения темпов роста мировой экономики - все эти события взаимосвязаны и произошли за период менее 1 года.

Фактически, чрезвычайно тесная взаимосвязанность и переплетенность финансовых систем привела к того, что кризис на американском рынке перерос в кризис мировой экономики. 


\section{ЛИТЕРАТУРА}

1. Греф Г., Юдаева К. Российская банковская система в условиях кризиса // вопросы экономика. — 2009. — № 7. — C. 4-14.

2. Григорьев Л., Салихов М. Финансовый кризис — 2008: вхождение в мировую рецессию // Вопросы экономики.— № 12.—C. $27-45$.

3. Ершов М. Кризис 2008 года: «Момент истины для глобальной экономики и новые возможности для России» // Вопросы экономики. — № 12 . — С. 4-26.

4. Мельник А. А. Теоретические подходы освещения финансовых кризисов // Наука и экономика — 2009. — № 4 (16). — C. 106-110.

5. Мищенко В., Сомик А. Ликвидность банковской системы: экономическая сущность, структура и методологический подход к анализу // Вестник Национального банка. - 2008. - № 11.— 6 .

6. Мищенко С. Критерии и показатели оценки стабильности функционирования финансового сектора // Вестник Национального банка. — 2008. — № 9. C. 36-45.

7. Монтес М.Ф., Попов В. В. «Азиатский вирус» или «голландская болезнь»? Теория и история валютных кризисов в России и других странах: Пер. с англ.—- М.: Дело, 1999.- $-136 \mathrm{c}$.

8. Рыжий К. Финансовые кризисы: теория, история, политика.—- М.: новое знание, 2003.- 399 с.

9. Швайка М. Мировой финансовый кризис: причины возникновения и пути преодоления [Электронный ресурс].— Pежим доступа: http:// soskin.info/ ea/2008/11-12/200803.html

10. Киндлбергер К. П. Мании, паники и крах: Макмиллан. — Лондон, 1978 год. - С. 128.

11. Кругман П. А. Модель кризиса платежного баланса // журнал денег, кредита и финансов. Банковское дело.— 1979. — Том. 11, № 3.— С. $311-325$.

12. Кузнецова А., Джулай В. мировой финансовый рынок нестабильности: антикризисные аспекты / вызовы современности. Современное предпринимательство в условиях глобализации: Научное издание. - Краков, 2010. - С. 25-32.

(с) Марьянов Дмитрий Вадимович ( pol2244@yandex.ru)

Журнал «Современная наука: актуальные проблемы теории и практики»

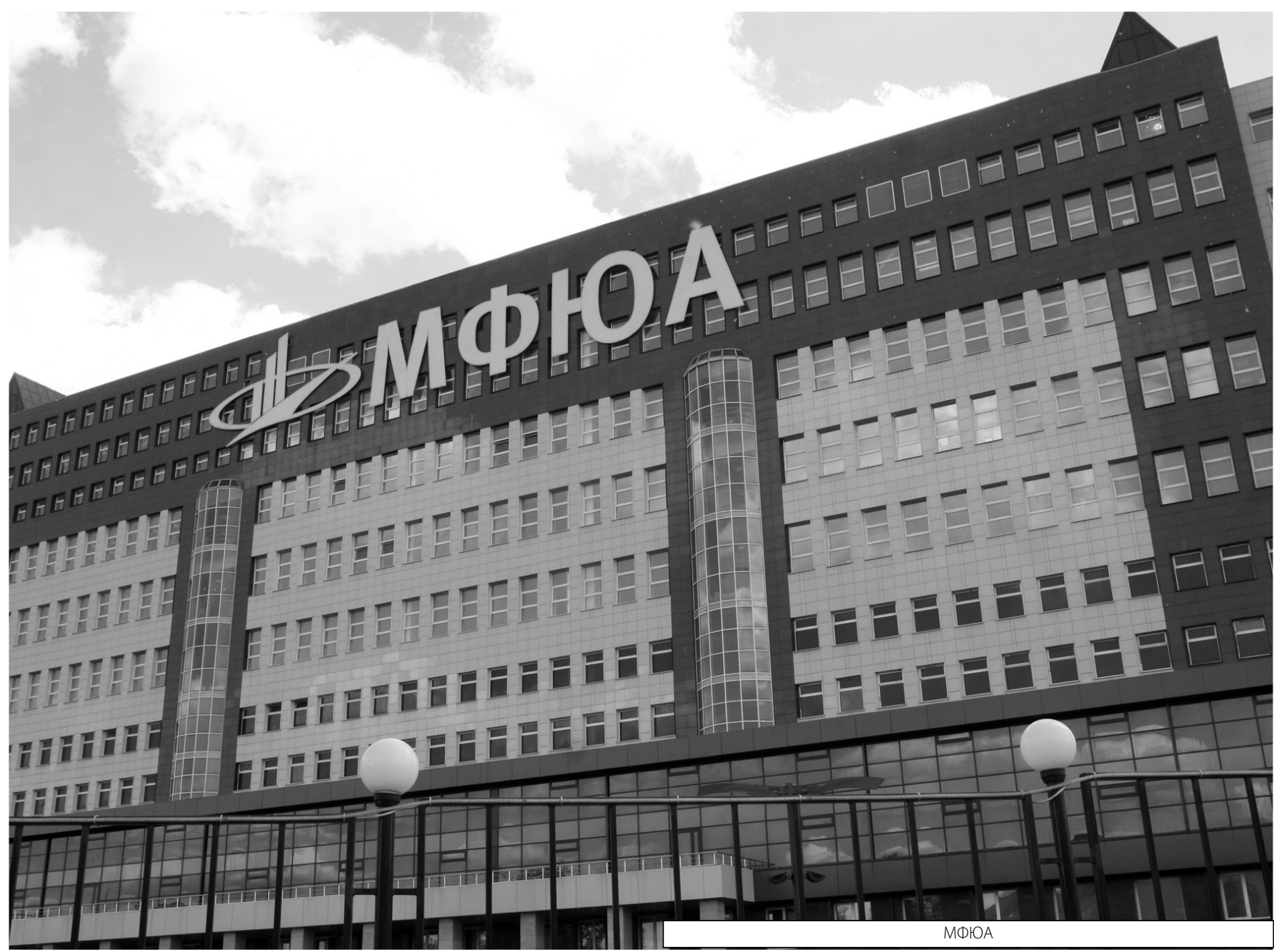

